We thank Ms. Rossella Mercuri and all the staff of St. Jude Medical Italia, Valve Division, for their assistance during the study on the St. Jude Medical HP aortic prosthesis.

\section{REFERENCES}

1. Odell JA, Durandt J, Shama DM, Vythilingum S. Spontaneous embolization of a St. Jude prosthetic mitral valve leaflet. Ann Thorac Surg 1985;39:569-72.

2. Hasse J. Escaped leaflet in a St. Jude Medical mitral prosthesis. In: DeBakey ME, editor. Advances in cardiac valves: clinical perspectives. New York: Yorke Medical Books, 1983:115-23.

3. Hjelms E. Escape of a leaflet from St. Jude Medical prosthesis in the mitral position. Thorac Cardiovasc Surg 1983;31:310-2.

4. Klepetko W, Moritz A, Mlczoch J, Schurawitzki H, Domanig E, Wolner E. Leaflet fracture in Edwards-Duromedics bileaflet valves. J Thorac Cardiovasc Surg 1989;97:90-4.

\title{
TRANSCATHETER EMBOLIZATION OF MYCOTIC ILIAC ANEURYSM AFTER AORTIC VALVE REPLACEMENT BECAUSE OF BACTERIAL ENDOCARDITIS
}

\author{
C. Akomea-Agyin, FRCS, J. F. Reidy, FRCR, and P. B. Deverall, FRCS, London, United Kingdom
}

Mycotic aneurysms have been reported to occur in about $15 \%$ of cases of infective endocarditis. ${ }^{1}$ Sudden rupture of these aneurysms is life threatening in the case of intracranial and visceral aneurysms, yet their detection and prediction of rupture are not always possible even with arteriography. ${ }^{2}$ The role of operation in the treatment of these aneurysms is well established, but operation is not always feasible because of difficult anatomic locations or multiplicity of aneurysms. Selective transcatheter embolization to occlude the feeding artery can produce thrombosis of the aneurysm and obviate the need for operation. Though experience with this technique is limited, more and more cases of its successful use are being reported. We present a case of a mycotic aneurysm of a branch of the superior gluteal artery diagnosed by selective arteriography and successfully treated by embolization with steel coils.

A 55-year-old man was admitted to the hospital with a 4-week history of increasing shortness of breath, fever, and rigors. He was in hemodynamically stable condition and an early diastolic murmur was heard over the aortic area. There were no splinter hemorrhages or other evidence of peripheral embolization. Laboratory study results were hemoglobin $9.5 \mathrm{gm} / \mathrm{dl}$, white blood cell count $11.9 \times 10^{9} / \mathrm{L}$, urea $553 \mathrm{mg} / \mathrm{L}$, and creatinine $13 \mathrm{mg} / \mathrm{L}$. Liver function test results were within normal limits as was

From the Department of Cardiothoracic Surgery and Radiology, United Medical and Dental Schools, Guy's Hospital, London, United Kingdom.

Received for publication. March 12, 1996; accepted for publication May 21, 1996.

Address for reprints: J. Reidy, FRCR, Consultant Radiologist, Guy's Hospital, St. Thomas Street, London SE1 9RT, United Kingdom.

J Thorac Cardiovasc Surg 1996;112:1671-2

Copyright (C) 1996 by Mosby-Year Book, Inc.

$0022-5223 / 96 \$ 5.00+0 \quad \mathbf{1 2 / 5 4 / 7 5 1 9 9}$ a coagulation screen. Chest x-ray films showed a normalsized heart with evidence of pulmonary venous hypertension. Transthoracic and transesophageal echocardiography demonstrated severe aortic regurgitation and large vegetations attached to the valve leaflets. A diagnosis of acute bacterial endocarditis was made and blood cultures isolated Streptococcus mitis sensitive to penicillin and gentamicin.

After 7 days of antibiotic therapy the patient underwent aortic valve replacement with the use of cardiopulmonary bypass. The operative findings were of a bicuspid aortic valve destroyed by vegetations and a small abscess cavity in the annular area. After the aortic valve was excised and all the infected tissue cleared the abscess cavity was obliterated and a 23R CarboMedics bileaflet mechanical valve (CarboMedics, Inc., Austin, Texas) was implanted with interrupted 2-0 Ethibond polyester sutures (Ethicon, Inc., Somerville, N.J.). The patient made a good postoperative recovery and intravenous antibiotic therapy was continued for 2 weeks. Warfarin therapy was started on the first postoperative evening with the aim of maintaining the international normalized ratio between 2.5 and 3.5 .

On postoperative day 8 a large painful swelling suddenly developed in the right buttock. This was thought to be a hematoma related to the anticoagulation. Aspirate of the hemotoma was sterile. The patient remained well and showed no signs of local or generalized sepsis. The hematoma was slow to resolve but he was well enough to be discharged from the hospital on postoperative day 21 . He received antibiotics for a total of 6 weeks and anticoagulation therapy was continued. At 3-month follow-up the swelling was smaller and nontender.

Seven months after his hospital discharge while still receiving anticoagulation he noticed a sudden increase in the size of the swelling, which also became excruciatingly painful. Ultrasonography showed a large blood-containing cavity in the right gluteal region. The international normalized ratio was within the target range. A selective right internal iliac arteriogram showed a branch of the superior 


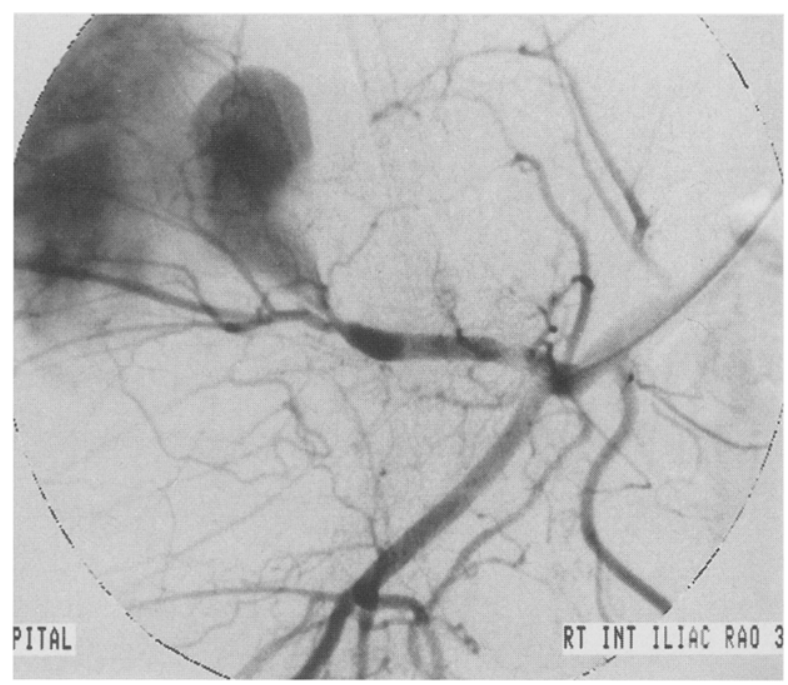

Fig. 1. Right internal iliac arteriogram showing contrast leaking from branch of superior iliac artery into large space.

gluteal artery with contrast leaking from it into a large space in the region of the hematoma (Fig. 1). This was believed to be a mycotic aneurysm that had ruptured. This artery at this point was selectively catheterized and then with the catheter tip just proximal to the neck of the aneurysm, three steel 0.038-inch coils (William Cook Europe Als, Bjaerverskov, Denmark) were placed in a small cluster in the artery. The postembolization study showed no filling of the hematoma and occlusion of the feeding artery (Fig. 2). The neighboring arteries were spared. After the embolization there was a significant reduction in pain but the mass was unchanged in size. He has since slowly recovered and the muscle wasting around the buttock has improved.

Mycotic aneurysms develop in about $15 \%$ of patients with infective endocarditis. ${ }^{1}$ They are potentially life threatening if they rupture. An overall mortality rate of $67 \%$ has been reported. ${ }^{3}$ Any artery can be affected but the intracranial arteries seem to be prone with $5 \%$ of patients having intracranial hemorrhage in the acute phase of endocarditis. ${ }^{4}$ A spectrum of arterial injury occurs in infective endocarditis resulting in mycotic aneurysms. Hart, Kagon-Hullet, and Joerns ${ }^{2}$ have postulated that sterile emboli may cause infarcts, which undergo secondary hemorrhagic transformation. This is usually mild but in the presence of anticoagulation can be more dramatic as in this case report. Anticoagulation was necessary because of the presence of a mechanical heart valve.

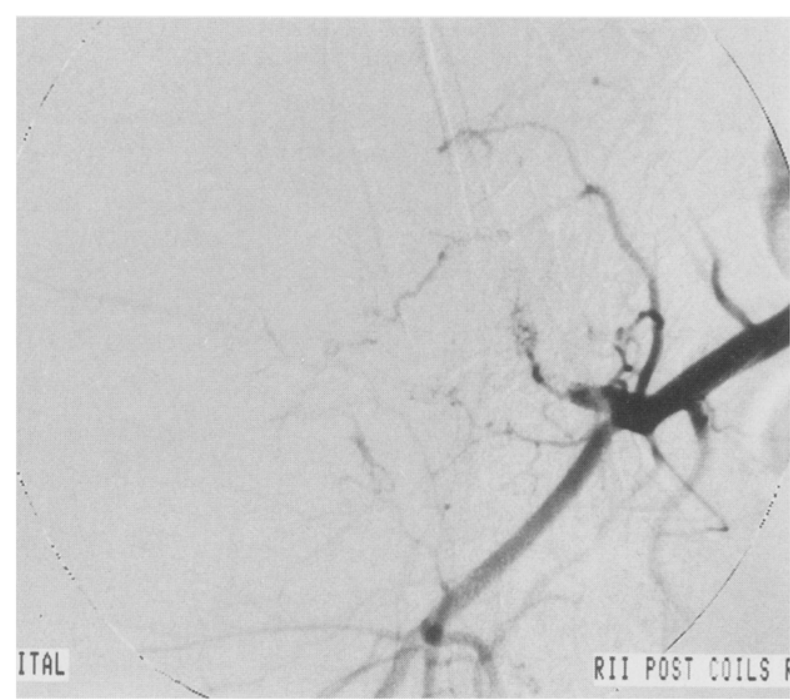

Fig. 2. Postembolization study showing no filling of hematoma and occlusion of feeding artery.

Transcatheter embolization of bleeding or pathologic vessels is a well-established technique and both aneurysms and pseudoaneurysms have been effectively occluded. However, use of this therapeutic procedure in mycotic aneurysms is still limited because of various considerations. The walls of these aneurysms are thin and weak and are prone to rupture during the procedure. In addition, there is the risk of chronic infection because foreign materials are introduced to a potentially infected area. This, however, did not seem to have been a problem in this case and other cases reported. This approach for dealing with mycotic aneurysms is therefore an acceptable option for some patients.

\section{REFERENCES}

1. Bullock R, Van Dellen JR. Rupture of bacterial intra-cranial aneurysm following replacement of cardiac valves. Surg Neurol 1982;17:9-11.

2. Hart RG, Kagon-Hullet K, Joerns SE. Mechanisms of intracranial hemorrhage in infective endocarditis. Stroke 1987;18: 1048-56.

3. Gonda RLJ, Gutierrez OH, Azodo MVU. Mycotic aneurysms of the aorta: radiologic features. Radiology 1988;168:343-6.

4. Le Cam B, Guivarch G, Boles JM, Garre M, Cartier F. Neurologic complications in a group of 86 bacterial endocarditis. Eur Heart J 1984;5(suppl C):97-100. 